\title{
Experience with Esophagogastrointestinal Transit Scintigraphy in the Initial 229 Patients: Multiple Regions of Dysmotility Are Common
}

\author{
Harvey A. Ziessman ${ }^{1}$, Mathurika Jeyasingam ${ }^{1}$, Ahsan U. Khan ${ }^{2}$, Zsuzsanna McMahan ${ }^{3}$, and Pankaj J. Pasricha ${ }^{4}$ \\ ${ }^{1}$ Russell H. Morgan Department of Radiology and Radiological Science, Johns Hopkins University School of Medicine, Baltimore, \\ Maryland; ${ }^{2}$ Department of Radiology, West Virginia University, Morgantown, West Virginia; ${ }^{3}$ Division of Rheumatology, Department \\ of Medicine, Johns Hopkins University School of Medicine, Baltimore, Maryland; and ${ }^{4}$ Division of Gastroenterology and Hepatology, \\ Department of Medicine, Johns Hopkins University School of Medicine, Baltimore, Maryland
}

The purpose of this investigation was to review our experience with our comprehensive esophagogastrointestinal transit study in the first 229 patients. This scintigraphic study analyzes the motility of the entire gut, from the esophagus through the rectosigmoid colon. Methods: Data were reviewed for our first 2 y of experience with this examination (184 women and 45 men aged 20-79 y [mean \pm $\mathrm{SD}, 44 \pm 16 \mathrm{y}]$ ). Patients were referred with symptoms suggestive of a motility disorder. They first swallowed ${ }^{111}$ In-diethylenetriaminepentaacetic acid in water for the esophageal-swallow study and then $300 \mathrm{~mL}$ for a $30-\mathrm{min}{ }^{111} \mathrm{In}$ water-only study, followed by 120 $\mathrm{mL}$ of ${ }^{111}$ In water simultaneously with the solid standardized ${ }^{99 m T c}$ egg-substitute meal. Images and quantification were obtained for esophageal transit, water-only gastric emptying, water-with-solid gastric emptying, small-bowel transit, and colonic transit. Results: Of the 229 patient studies, $45(20 \%)$ were normal. The remaining $184(80 \%)$ had at least 1 region of dysmotility, for a total of 336 regions of abnormal motility. A single region of dysmotility was seen in 92 patients (50\%), 2 regions in 50 (27\%), 3 regions in $26(14 \%), 4$ regions in $12(7 \%)$, and 5 regions in $4(2 \%)$. There was a poor correlation between the results of the water-only study and water with the solid meal. Three different patterns of delayed colonic transit were seen. Patient symptoms were often not predictive of the scintigraphic findings. Conclusion: This study highlights the frequent occurrence of dysmotility in more than 1 region of the gastrointestinal tract in patients with a suspected motility disorder and the frequent concurrence of both upper- and lower-tract dysmotility in the same patients. It provides information to referring physicians regarding which motility disorders may be causing the patient symptoms, why the patient is or is not responding to the present therapy, and if and what additional workup and therapy may be needed.

Key Words: gastric scintigraphy; gastrointestinal transit; intestinal transit scintigraphy

J Nucl Med 2021; 62:115-122

DOI: 10.2967/jnumed.120.243527

\footnotetext{
Received Feb. 14, 2020; revision accepted May 5, 2020.

For correspondence or reprints contact: Harvey A. Ziessman, Johns Hopkins University School of Medicine, 601 N. Caroline St., JHOC 3231, Baltimore, MD 21287.

E-mail: hziessm1@jhmi.edu

Published online Jun. 1, 2020.

COPYRIGHT (C 2021 by the Society of Nuclear Medicine and Molecular Imaging.
}

A t most imaging centers, gastric emptying scintigraphy is a commonly requested nuclear medicine study because it provides important functional information on gastric motility not available from other methodologies. However, there has been concern that only $30 \%-60 \%$ of symptomatic patients with clinically suspected functional gastroparesis have abnormal results on radionuclide gastric emptying studies (1-3).

More recently, there has likely been an increase in the positivity rate of gastric emptying studies, for 2 reasons. First, a consensus recommendation for a 4-h gastric emptying study was published in the nuclear medicine and gastroenterology literature and is now standard $(4,5)$. The 4-h study has proven to be more sensitive for detection of gastroparesis than the shorter studies (e.g., $2 \mathrm{~h}$ ) commonly used in the past (6,7). A $30 \%$ increase in positivity has been reported at $4 \mathrm{~h}$ compared with $2 \mathrm{~h}(8)$. Furthermore, the addition of a clear liquid (water) emptying study increases the sensitivity for detection of gastroparesis. Multiple investigations have found that of patients referred with a suspected gastric motility disorder who have normal results for solid gastric emptying, 25\%-30\% will have delayed liquid emptying (9-12).

However, a gap still persists in our ability to detect abnormal emptying in patients referred with symptoms suggestive of a gastric motility disorder. Although gastric dysmotility symptoms are commonly associated with postprandial upper abdominal symptoms of nausea, vomiting, and abdominal discomfort, and intestinal disorders are most commonly associated with lower abdominal pain, bloating, diarrhea, and constipation, there may be an overlap in symptoms of upper- and lower-intestinal dysmotility (13-15). Thus, the addition of small- and large-bowel intestinal transit scintigraphy to the gastric emptying study may be of value by confirming or excluding dysmotility in these additional regions and pinpointing the regions of the gastrointestinal tract causing the patient's symptoms.

Whole-gut transit radionuclide studies that combine gastric emptying and small- and large-bowel transit studies into a single study have been described and are routinely performed at a few centers $(16,17)$. We have been providing our comprehensive esophagogastrointestinal transit study since 2014. Our unique methodology has been previously published, along with our reference values and our initial clinical experience (18).

In the first $2 \mathrm{y}$ of offering this test, 229 patients completed it. This article describes the results of this scintigraphic study for 


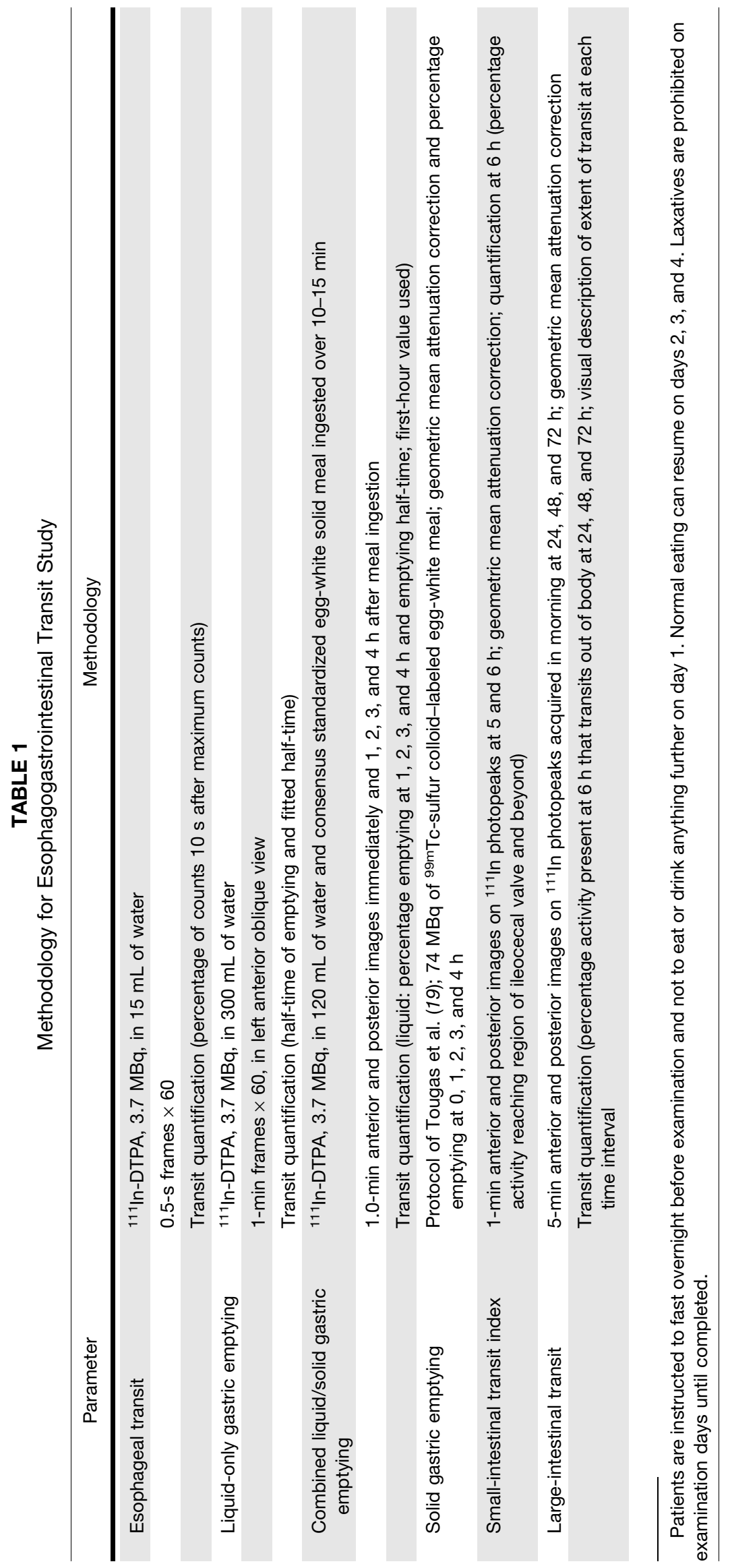

116 The Journal of Nuclear Medicine • Vol. 62 • No. 1 • January 2021 
those patients. Of particular interest was that many patients were found to have abnormal motility at more than 1 site and not infrequently in both the upper and the lower gastrointestinal tract.

\section{MATERIALS AND METHODS}

\section{Patient Population}

The institutional review board at Johns Hopkins University approved this retrospective study, and the requirement to obtain informed consent was waived.

The patients completed the esophagogastrointestinal transit study between August 2014 and November 2016 and included 45 men and 184 women (age range, 20-79 y; mean \pm SD, $44 \pm 16$ y). Most patients were referred from the Johns Hopkins Gastrointestinal Motility Clinic, some by other Johns Hopkins gastroenterologists, and a minority from the rheumatology clinic. The patients usually had either predominantly lower-abdominal complaints (49\%), a combination of upper- and lower-abdominal complaints $(31 \%)$, or a poor response to their present treatment after having had a prior radionuclide gastric emptying study (20\%).

\section{Scintigraphic Methodology}

The studies began on a Monday morning. The patients were asked to fast overnight before beginning the study, not to take laxatives the day before or during the study, and-for at least $3 \mathrm{~d}$ before and during the study - to withhold other medications that might affect gastrointestinal motility.

The first day of the study included esophageal transit, then liquidonly (water) gastric emptying followed by simultaneous liquid and solid gastric emptying, and then small-bowel transit, for a total imaging time of $6 \mathrm{~h}$. After this first day, there were no food or activity limitations for the duration of the study. Imaging was subsequently performed at 24,48 , and $72 \mathrm{~h}$ to quantify colonic transit, requiring only one 5-min anterior and posterior morning image. Our methodology and quantification are detailed in Table 1.

The abnormal values used for this study were derived from our prior publication (18). Abnormal esophageal swallow was considered to be less than an $83 \%$ transit of counts $10 \mathrm{~s}$ after maximum counts; abnormal liquid-only gastric emptying, a half-time of more than 25 min; abnormal liquid with solid meal, less than $39 \%$ emptying at $1 \mathrm{~h}$; abnormal solid gastric emptying, less than $90 \%$ emptying at $4 \mathrm{~h}$; abnormal small-bowel transit, less than $49 \%$ arrival at the ileocecal valve by $6 \mathrm{~h}$; and abnormal large-bowel transit, less than $67 \%$ by $72 \mathrm{~h}$.

\section{RESULTS}

Of the 229 patient studies, 45 (20\%) were interpreted as normal. The remaining 184 patients $(80 \%)$ had at least 1 region of dysmotility, with a total of 336 abnormal regions. A single region of dysmotility was seen in 92 patients $(50 \%)$ (Table 2). The regions involved were the esophagus (6 patients) (Fig. 1), gastric

TABLE 2

Distribution and Frequency of 1 Abnormal Motility Region in Patients

\begin{tabular}{ccccccc}
\hline $\begin{array}{c}\text { Total } \\
\text { patients } \\
(n)\end{array}$ & Esophagus & $\begin{array}{c}\text { Stomach, } \\
\text { liquid } \\
\text { only }\end{array}$ & $\begin{array}{c}\text { Stomach, } \\
\text { liquid } \\
\text { with solid }\end{array}$ & $\begin{array}{c}\text { Stomach, } \\
\text { solid }\end{array}$ & $\begin{array}{c}\text { Colon or } \\
\text { bowel }\end{array}$ & $\begin{array}{c}\text { rectosigmoid } \\
\text { region }\end{array}$ \\
\hline 92 & 6 & 10 & 1 & 6 & 10 & 59 \\
\hline
\end{tabular}

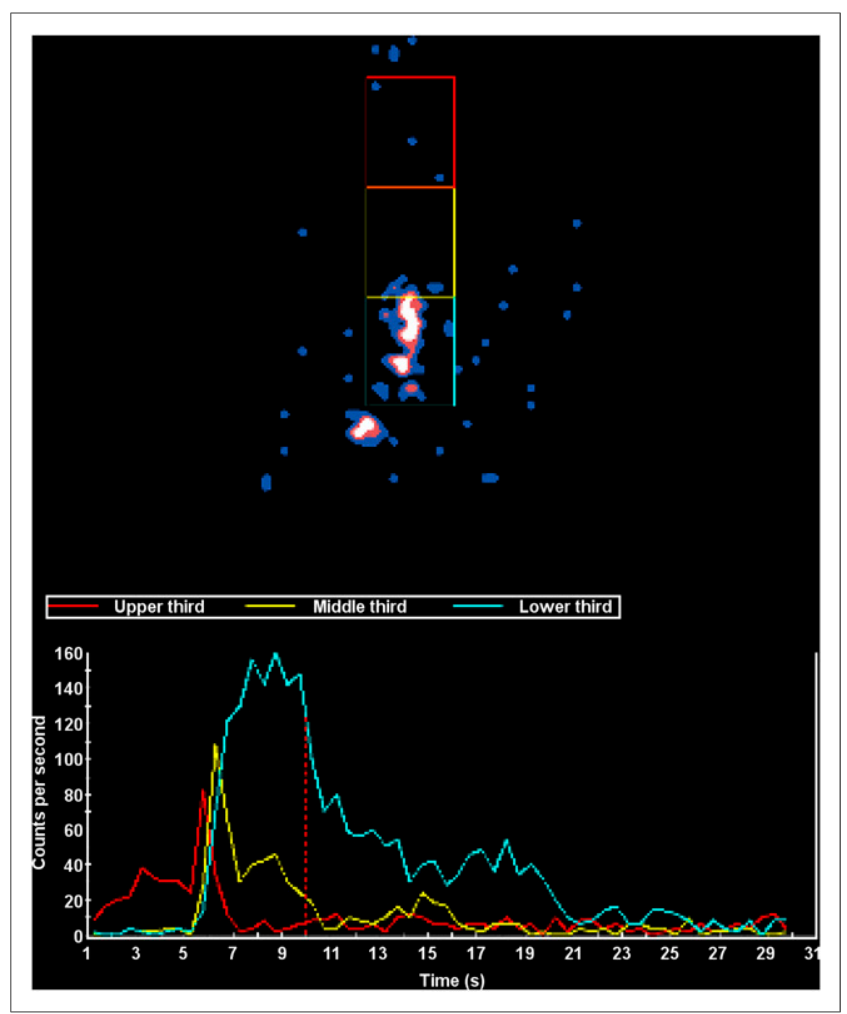

FIGURE 1. Delayed esophageal transit. (Top) Single 0.5-s dynamic frame showing retained activity in esophagus and some transit to stomach. (Bottom) Time-activity curves show good transit in the upper esophagus, but poor transit in the middle and especially the lower third of the esophagus. Total percentage esophageal emptying was $43 \%$ (abnormal emptying is $<83 \%$ ).

liquid only (10 patients) (Fig. 2A), gastric liquid with the solid meal (1 patient) (Fig. 2B), solid gastric emptying (6 patients) (Fig. 2C), small intestine (10 patients), and large intestine (59 patients) (Figs. 3, 4, and 5; Table 2).

Two regions of gastrointestinal dysmotility were detected in 50 patients (27\%) (Table 3), 3 regions in 26 patients (14\%) (Table 4), 4 regions in 12 patients (7\%) (Table 5), and 5 regions in 4 patient (2\%) (Table 6). Forty-three of 49 patients with solid-meal gastroparesis had additional regions of gastrointestinal dysmotility (Tables 3-6).

The liquid-only studies and the liquid-with-solid-meal studies did not correlate well with each other. The former was positive in 45 patients; the latter, in 32 patients. Both were positive in the same patients in only 14 instances.

Delayed transit was the predominant finding in the patients with dysmotility. Rapid transit was less common; it was never seen in the esophagus and was seen only once for liquid-only gastric emptying, 3 times when liquid was combined with solid food, 6 times in solid gastric emptying, 7 times in the small bowel, and 3 times in the colon.

In the 15 patients with systemic sclerosis, all but 2 had delayed esophageal transit. These patients also had various other motility abnormalities. Eight had delayed solid-meal emptying, 6 had delayed colonic transit, and 9 had multiple regions of dysmotility, including liquid-only gastric emptying, liquid-with-solid gastric emptying, and small bowel. 


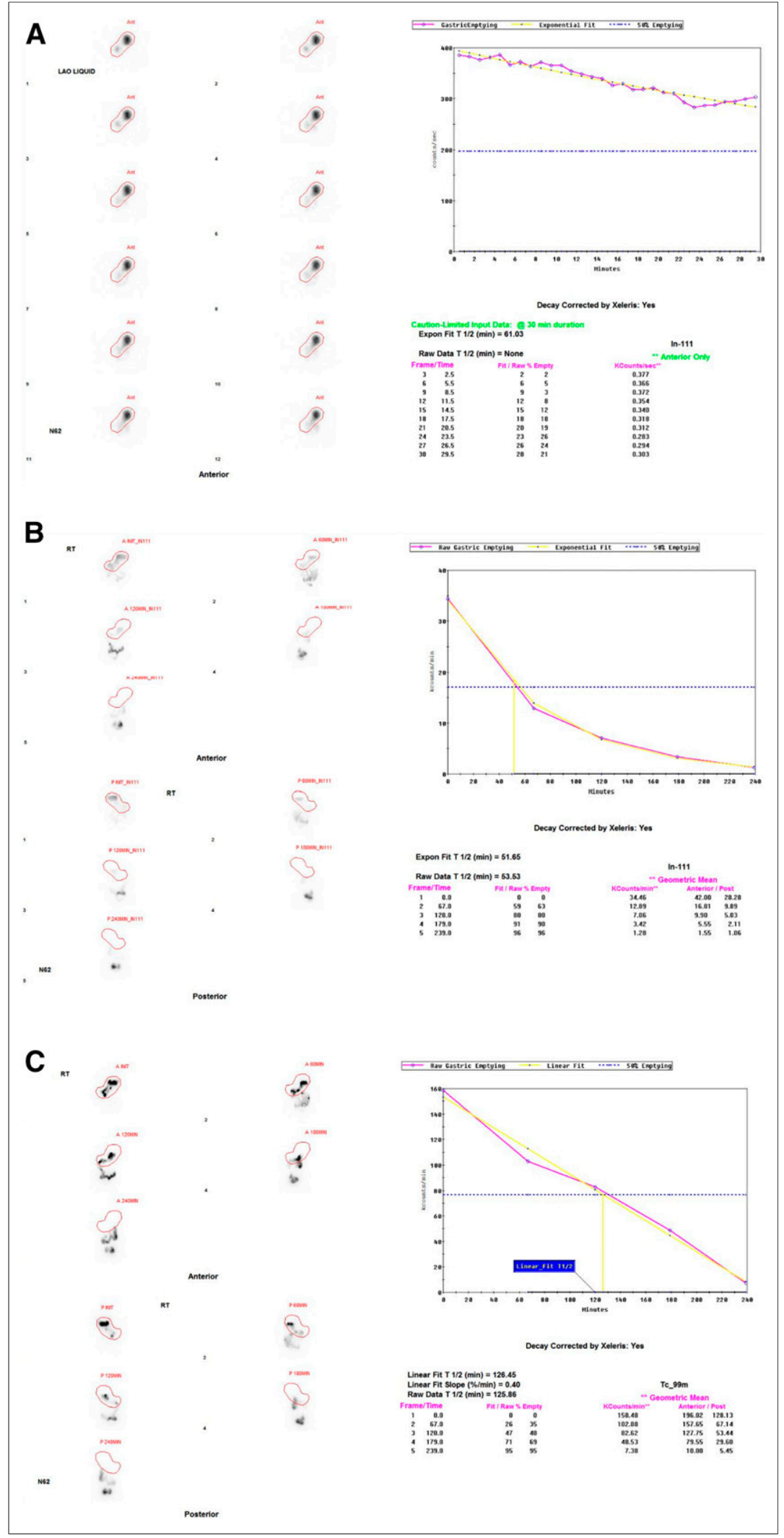

FIGURE 2. Abnormal clear-liquid-only emptying, normal liquid-with-solid emptying, and normal solid emptying in same patient. (A) Clear liquid only shows poor emptying, with delayed time-activity curve and half-time of clearance of $61 \mathrm{~min}$ (normal clearance is $<25 \mathrm{~min}$ ). (B) Clear liquid ingested with solid meal shows normal multiexponential pattern of clearance. (C) Solid-meal emptying is normal, with $95 \%$ emptying at $4 \mathrm{~h}$.
Three patterns were seen in patients with quantitatively delayed colonic transit (Figs. 3-5). Some patients had images showing transit throughout the entire colon and rectosigmoid region but with no or little excretion from the body $(62 \%)$, whereas others had proximal regional abnormal transit; that is, the radiotracer was seen transiting only to the ascending, transverse, or splenic flexure $(31 \%)$. A few patients had delayed excretion manifested by retention in the rectosigmoid region (7\%).

Some patient's symptoms predicted the scintigraphic findings. For example, in the colon, those with symptoms of diarrhea often had rapid colonic transit, whereas those with constipation often had delayed transit. However, in other patients, the symptoms did not predict the scintigraphic findings. Most patients had both upper- and lower-gastrointestinal symptoms. Although patients with delayed gastric emptying often had typical symptoms of dyspepsia, bloating, early satiety, and weight loss, many also had constipation (83\%) and diarrhea (17\%). Patients with delayed liquid-only results often had symptoms of dyspepsia, nausea, and vomiting, but many also had constipation or diarrhea. With small-bowel delayed transit, abdominal cramping was the dominant symptom (90\%), but many also complained of constipation $(75 \%)$. In patients with more than 1 region of dysmotility, symptoms overlapped and often were not predictive of the scintigraphic findings. Diffuse dysmotility was seen predominantly in patients with diabetic gastroparesis and poor glycemic control.

Management changed for patients with positive results, particularly those with multiple regions of dysmotility. A change in management occurred in $17 \%$ of patients with 1 region of dysmotility, in $34 \%$ of patients with 2 regions, in $38 \%$ with 3 regions, and in more than $50 \%$ with $4-5$ regions.

\section{DISCUSSION}

Various radionuclide solid gastric emptying methodologies have been used over the years at different imaging centers, with different study lengths, meals, quantification methods, and reference values. However, a specific standardized 4-h protocol published by Tougas et al., with multicenter reference values based on 123 subjects, is now recommended (19); consensus recommendations have been published in both the nuclear medicine and the gastroenterology literature $(4,5)$. At a few centers, combined solid and liquid gastric emptying studies are routinely performed (12,20). Small- and large-intestinal transit studies have been described and are performed at a limited number of imaging centers, often using different methodologies, radiotracers, and reference values (21-24). 


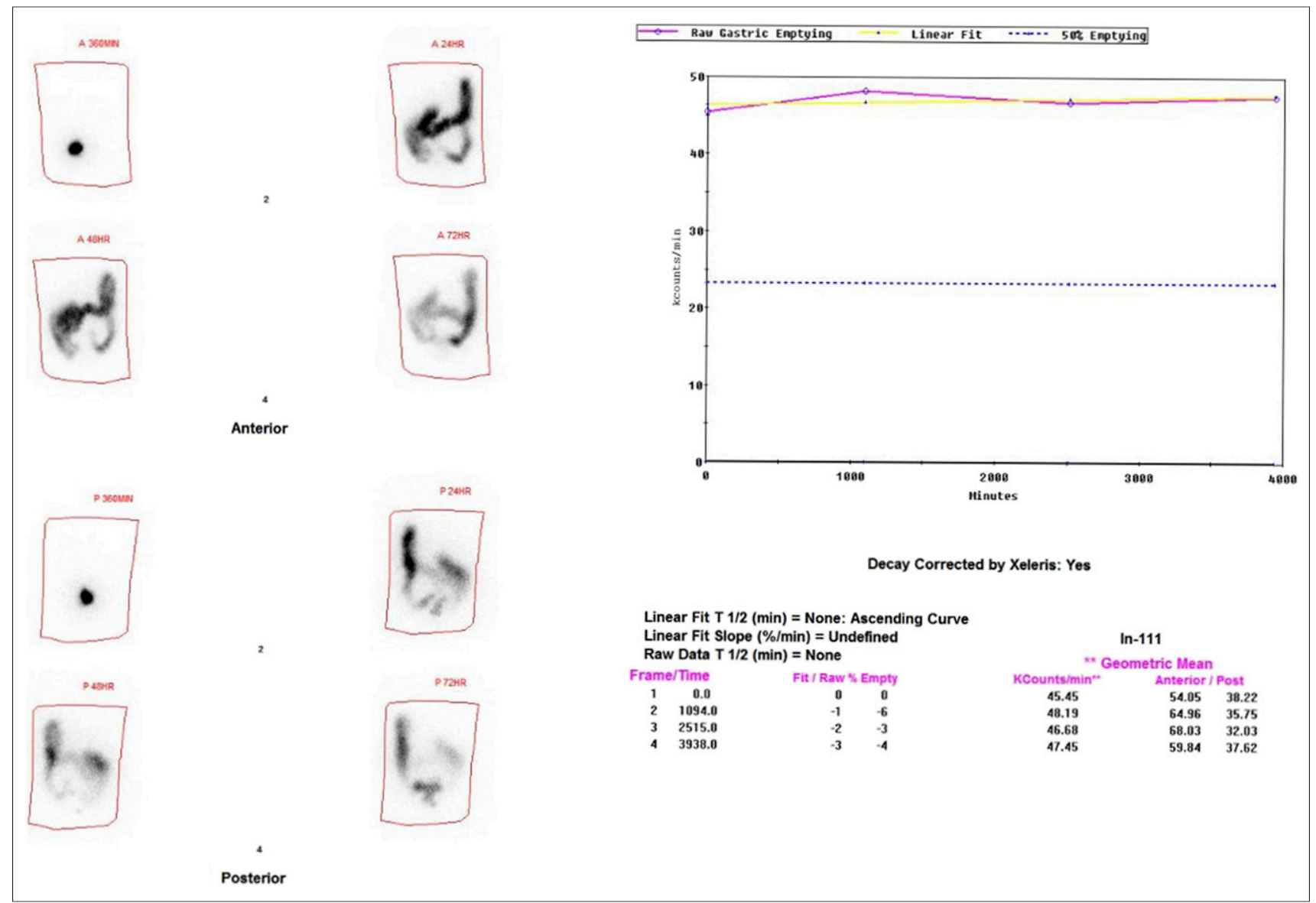

FIGURE 3. Entire-colon delayed transit. Regions of interest are drawn around activity at $6,24,48$, and $72 \mathrm{~h}$ in anterior and posterior views. Activity at $6 \mathrm{~h}$ (upper left) is mostly at ileocecal valve. It was used as denominator for calculation of percentage colonic transit at each subsequent interval. Percentage transit (excretion from body) is $0 \%$. Images show transit of activity to descending colon on anterior view and to rectosigmoid region on posterior view.

Whole-gut transit scintigraphy was first described by the Mayo Clinic in 1995 and subsequently at Temple University in 2000 $(16,17)$. This terminology refers to combining gastric and small-

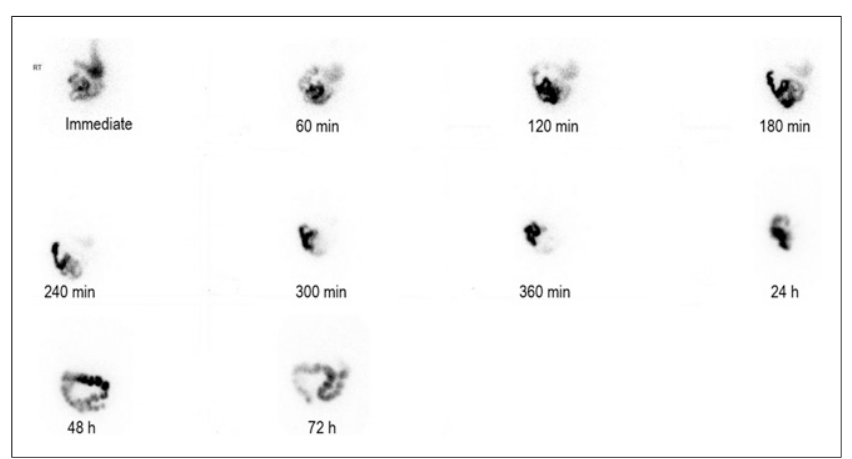

FIGURE 4. Proximal-colon delayed transit. Anterior images are shown at all imaging time points. In immediate image, stomach is seen superiorly. At $60-180 \mathrm{~min}$, most activity is in proximal small bowel. By 240 min, activity is in distal small bowel. By 360 min, most activity is at ileocecal valve. A region of interest is placed around this activity to quantify small-bowel transit (activity that has reached ileocecal value and beyond at $360 \mathrm{~min}$ ). At $24 \mathrm{~h}$, most activity is in cecum. At $48 \mathrm{~h}$, activity has reached transverse colon. At $72 \mathrm{~h}$, activity distribution is similar; most is distal although not reaching splenic flexure. Figure 5 shows quantification for this patient. and large-intestinal transit into 1 study. The Mayo Clinic uses a radiopharmaceutical not approved by the Food and Drug Administration, a $\mathrm{pH}$-sensitive methacrylate-coated capsule containing ${ }^{111}$ In-labeled activated charcoal particles. The capsule dissolves on reaching the alkaline terminal ileum, releasing the radionuclide. It can be combined with a ${ }^{99 m}$ Tc-labeled solid gastric emptying meal to examine both the upper and the lower gastrointestinal tracts (25). Temple uses ${ }^{111}$ In-diethylenetriaminepentaacetic acid (DTPA) in water combined with a solid meal for its whole-gut studies (16). The utility of ${ }^{111} \mathrm{In}$-DTPA is that it is not absorbed in the gastrointestinal tract and has a relatively long half-life (2.8 d), allowing for the 3- to 4-d imaging study. The rate of transit of ${ }^{111}$ In-DTPA correlates well with both radiopaque markers and ${ }^{131}$ I cellulose (26,27).

At Johns Hopkins, we have been performing our comprehensive esophagogastrointestinal scintigraphy since 2014. We published our methodology and initial experience in 18 patients in 2015 (18). This methodology varies from other published whole-gut scintigraphic methods in several ways. First, we perform an initial esophageal transit study. Then, we study liquid gastric emptying in 2 ways, with clear liquid (water) only and then with simultaneous ingestion of additional ${ }^{111}$ In water with a solid meal. Our method of quantitating colonic transit also differs from prior described methods. We do not calculate a geometric center of activity as some centers have described; rather, we determine the percentage 


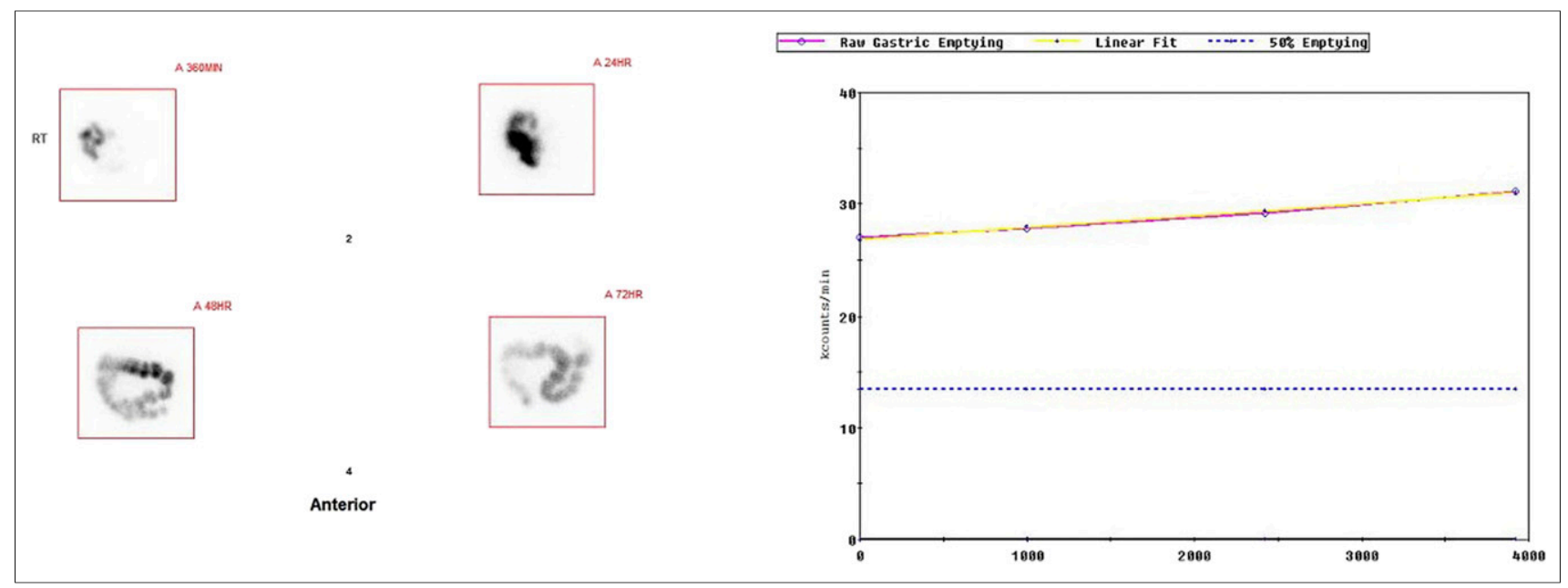

FIGURE 5. Colonic images and quantification from patient in Figure 4 (posterior views are not shown but were used for geometric mean quantification) shows no transit (0\%) out of body and regional transit delay. Time-activity curve rises slightly because of imperfect attenuation correction. Dotted horizontal line represents $50 \%$ emptying.

transit, that is, the amount of activity that has left the body at 24 , 48 , and $72 \mathrm{~h}$, calculated similarly to the method used for gastric emptying. In addition, we provide a visual description of the extent of transit of the radionuclide at each time point. The geometriccenter method requires drawing 5-7 regions of interest for the colon. It is time-consuming, and invariably, different ROIs are drawn by different technologists and physicians. We have shown that the 2 different methods correlate quite well (18).

The reason that we include 2 different liquid studies-a 30min water $(300 \mathrm{~mL})$-only study with ${ }^{111} \mathrm{In}$-DTPA followed by ${ }^{111}$ In water $(120 \mathrm{~mL})$ ingested simultaneously with the solid meal and measured at $0,1,2,3$, and $4 \mathrm{~h}$-is that our experience suggested that the 2 methods often provide different results. This

TABLE 3

Distribution and Frequency of Patients with 2 Abnormal Regions of Motility

\begin{tabular}{|c|c|c|c|c|c|c|}
\hline $\begin{array}{c}\text { Patients } \\
\text { (n) }\end{array}$ & Esophagus & $\begin{array}{l}\text { Stomach, } \\
\text { liquid only }\end{array}$ & $\begin{array}{l}\text { Stomach, } \\
\text { liquid with } \\
\text { solid }\end{array}$ & $\begin{array}{l}\text { Stomach, } \\
\text { solid }\end{array}$ & $\begin{array}{l}\text { Small } \\
\text { bowel }\end{array}$ & $\begin{array}{l}\text { Colon or } \\
\text { rectosigmoid } \\
\text { region }\end{array}$ \\
\hline 2 & $x$ & $x$ & & & & \\
\hline 2 & $x$ & & & $x$ & & \\
\hline 3 & $x$ & & & & $x$ & \\
\hline 10 & $x$ & & & & & $x$ \\
\hline 1 & & $x$ & & $x$ & & \\
\hline 1 & & $x$ & & & $x$ & \\
\hline 9 & & $x$ & & & & $x$ \\
\hline 3 & & & $x$ & $x$ & & \\
\hline 1 & & & $x$ & & $x$ & \\
\hline 4 & & & $x$ & & & $x$ \\
\hline 1 & & & & $x$ & $x$ & \\
\hline 10 & & & & $x$ & & $x$ \\
\hline 3 & & & & & $x$ & $x$ \\
\hline Total pati & ents $=50$ & & & & & \\
\hline
\end{tabular}

possibility was confirmed in this investigation and suggests to us a different pathophysiology for the 2 methods, although the explanation for this difference is uncertain and requires further study.

Demand for our comprehensive study continues to grow, and we are now doing 5-7 studies a week, or approximately 250 studies a year. A bias in our referral pattern may be that many patients are referred with suspected disease in the lower gastrointestinal tract, others because of symptoms suggestive of issues with both the upper and the lower gastrointestinal tracts, and others because of a poor therapeutic response to gastroparesis reported on a prior gastric emptying study.

This paper highlights the frequency with which transit disorders in both the upper and the lower gastrointestinal tracts occur in the same patients. A report from Temple University in 2000 describing its whole-gut transit scintigraphy study stated that "some patients had a diffuse dysmotility disorder of the gastrointestinal tract" (15). This was similarly observed by Stivland et al. (28), but neither publication specified its frequency or whether dysmotility

TABLE 4

Distribution and Frequency of Patients with 3 Abnormal Regions of Motility

\begin{tabular}{|c|c|c|c|c|c|c|}
\hline $\begin{array}{c}\text { Patients } \\
\text { (n) }\end{array}$ & Esophagus & $\begin{array}{l}\text { Stomach, } \\
\text { liquid } \\
\text { only }\end{array}$ & $\begin{array}{l}\text { Stomach, } \\
\text { liquid } \\
\text { with } \\
\text { solid }\end{array}$ & $\begin{array}{l}\text { Stomach, } \\
\text { solid }\end{array}$ & $\begin{array}{l}\text { Small } \\
\text { bowel }\end{array}$ & $\begin{array}{l}\text { Colon or } \\
\text { rectosigmoid } \\
\text { region }\end{array}$ \\
\hline 3 & $x$ & $x$ & & $x$ & & \\
\hline 2 & $x$ & $x$ & & & & $x$ \\
\hline 4 & $x$ & & & $x$ & & $x$ \\
\hline 4 & $X$ & & & & $X$ & $X$ \\
\hline 4 & & $x$ & $x$ & & & $x$ \\
\hline 3 & & $x$ & & & $x$ & $x$ \\
\hline 2 & & & $x$ & $x$ & $x$ & \\
\hline 4 & & & $x$ & $x$ & & $x$ \\
\hline Total pat & ents $=26$ & & & & & \\
\hline
\end{tabular}


TABLE 5

Distribution and Frequency of Patients with 4 Abnormal Regions of Motility

\begin{tabular}{|c|c|c|c|c|c|c|}
\hline $\begin{array}{l}\text { Patients } \\
\text { (n) }\end{array}$ & Esophagus & $\begin{array}{l}\text { Stomach, } \\
\text { liquid } \\
\text { only }\end{array}$ & $\begin{array}{l}\text { Stomach, } \\
\text { liquid } \\
\text { with } \\
\text { solid }\end{array}$ & $\begin{array}{l}\text { Stomach, } \\
\text { solid }\end{array}$ & $\begin{array}{l}\text { Small } \\
\text { bowel }\end{array}$ & $\begin{array}{l}\text { Colon or } \\
\text { rectosigmoid } \\
\text { region }\end{array}$ \\
\hline 1 & $x$ & $x$ & & $x$ & & $x$ \\
\hline 1 & $x$ & $x$ & $x$ & $x$ & & \\
\hline 1 & $x$ & $x$ & & & $x$ & $x$ \\
\hline 1 & & $x$ & $x$ & $x$ & $x$ & \\
\hline 1 & $x$ & $x$ & $x$ & & $x$ & \\
\hline 2 & $x$ & & $x$ & $x$ & & $x$ \\
\hline 1 & & $x$ & $x$ & $x$ & $x$ & \\
\hline 1 & & $x$ & $x$ & & $x$ & $x$ \\
\hline 1 & & & $x$ & $x$ & $x$ & $x$ \\
\hline 1 & $x$ & & $x$ & $x$ & $x$ & \\
\hline 1 & & $x$ & & $x$ & $x$ & $x$ \\
\hline
\end{tabular}

Total patients $=12$ gastrointestinal tract, helping to explain patient symptoms or poor response to therapy.

\section{DISCLOSURE}

No potential conflict of interest relevant to this article was reported.

\section{KEY POINTS}

QUESTION: The aim of this investigation was to determine the clinical value of our comprehensive esophagogastrointestinal transit scintigraphic study in our first 229 patients.

PERTINENT FINDINGS: One region of dysmotility in the gastrointestinal tract was detected in $50 \%$ of patients, 2 regions in $27 \%, 3$ in $14 \%, 4$ in $7 \%$, and 5 in $2 \%$. Upper- and lower-gastrointestinal dysmotility was commonly seen in the same patient.

IMPLICATIONS FOR PATIENT CARE: This study permits referring physicians to appreciate which motility disorders may be causing the patient's symptoms, why a patient is or is not responding to present therapy, and what additional workup or therapy may be needed.
TABLE 6

Distribution and Frequency of Patients with 5 Abnormal Regions of Motility

\begin{tabular}{|c|c|c|c|c|c|c|}
\hline $\begin{array}{c}\text { Patients } \\
\text { (n) }\end{array}$ & Esophagus & $\begin{array}{l}\text { Stomach, } \\
\text { liquid } \\
\text { only }\end{array}$ & $\begin{array}{l}\text { Stomach, } \\
\text { liquid } \\
\text { with } \\
\text { solid }\end{array}$ & $\begin{array}{l}\text { Stomach, } \\
\text { solid }\end{array}$ & $\begin{array}{l}\text { Small } \\
\text { bowel }\end{array}$ & $\begin{array}{l}\text { Colon or } \\
\text { rectosigmoid } \\
\text { region }\end{array}$ \\
\hline 1 & & $x$ & $x$ & $x$ & $x$ & $x$ \\
\hline 3 & $X$ & $x$ & $x$ & $x$ & & $x$ \\
\hline
\end{tabular}

could occur in multiple separate regions of the gastrointestinal tract, for example, stomach and colon. Studies with the wireless motility capsule have also found that some patients have a diffuse motility disorder but also that patients may have dysmotility in more than 1 region of the gastrointestinal tract, upper and lower, and that the clinical presentation is often not predictive of regional transit delays (29). Different patterns of delayed colonic transit have been previously described, including a diffusely delayed pattern, delay limited to the proximal colon, and rectosigmoid dysfunction (30). To our knowledge, this was the first scintigraphic study to describe and quantify these 3 patterns of colonic dysmotility.

\section{CONCLUSION}

Esophagogastrointestinal transit scintigraphy provides referring physicians with valuable information on which motility disorder may be causing their patient's symptoms, why their patient is or is not responding to the present therapy, and if and what additional workup and treatment may be needed. Most importantly, to our knowledge, this was the first scintigraphic study to find that many patients have dysmotility in more than 1 region of the

\section{REFERENCES}

1. Thumshirn M. Pathophysiology of functional dyspepsia. Gut. 2002;51(suppl 1):i63-i66.

2. Quartero AO, De Wit NM, Lodder AC, et al. Disturbed solid phase gastric emptying in functional dyspepsia. Dig Dis Sci. 1998;43:2028-2033.

3. Tack J, Bisschops RAF, Sarnelli G. Pathophysiology and treatment of functional dyspepsia. Gastroenterology. 2004;127:1239-1255.

4. Abell TL, Camilleri M, Donohoe K, et al. Consensus recommendations for gastric emptying scintigraphy: a joint report of the American Neurogastroenterology and Motility Society and the Society of Nuclear Medicine. J Nucl Med Technol. 2008;36:44-54.

5. Abell TL, Camilleri M, Donohoe K, et al. Consensus recommendations for gastric emptying scintigraphy: a joint report of the American Neurogastroenterology and Motility Society and the Society of Nuclear Medicine. Am J Gastroenterol. 2008;103:753-763.

6. Thomforde GM, Camilleri M, Phillips SF, Forstrom LA. Evaluation of an inexpensive screening scintigraphic test of gastric emptying. J Nucl Med. 1995;36: 93-96.

7. Guo J-P, Maurer AH, Fisher RS, Parkman HP. Extending gastric emptying from 2 to 4 hours detects more patients with gastroparesis. Dig Dis Sci. 2001;46: 24-29.

8. Ziessman HA, Bonta DV, Goetze S, Ravich WJ. Experience with a simplified, standardized 4-hour gastric-emptying protocol. J Nucl Med. 2007;48:568572.

9. Horowitz M, Maddox AF, Wishart JM, et al. Relationships between oesophageal transit and solid and liquid gastric emptying in diabetes mellitus. Eur J Nucl Med. 1991;18:229-234.

10. Ziessman HA, Okolo PI, Mullin GE, Chander A. Liquid gastric emptying is often abnormal when solid emptying is normal. J Clin Gastroenterol. 2009;43: 639-643.

11. Ziessman HA, Chander A, Clarke JO, Ramos A, Wahl RL. The added diagnostic value of liquid gastric emptying compared with solid emptying alone. J Nucl Med. 2009;50:726-731.

12. Sachdeva P, Malhotra N, Pathikonda M, et al. Gastric emptying of solids and liquids for evaluation for gastroparesis. Dig Dis Sci. 2011;56:1138-1146.

13. Parkman HP, Yates K, Hasler WI, et al. Clinical features of idiopathic gastroparesis vary with sex, body mass, symptom onset, delay in gastric emptying and gastroparesis severity. Gastroenterology. 2011;140:101-115.

14. Parkman HP, Yates K, Hasler WI, et al. Similarities and differences between diabetic and idiopathic gastroparesis. Clin Gastroenterol Hepatol. 2011;9: 1056-1064.

15. Hasler WL, Rao SSC, McCallum RW, et al. Influence of gastric emptying and gut transit testing on clinical management decisions in suspected gastroparesis. Clin Transl Gastroenterol. 2019; in press 10.14309/ctg.0000000000000084. 
16. Bonapace ES, Maurer AH, Davidoff S, et al. Whole gut transit scintigraphy in the clinical evaluation of patients with upper and lower gastrointestinal symptoms. Am J Gastroenterol. 2000;95:2838-2847.

17. Charles F, Camilleri M, Phillips SF, et al. Scintigraphy of the whole gut: Clinical evaluation of transit disorders. Mayo Clin Proc. 1995;70:113-118.

18. Antoniou AJ, Raja S, El-Khouli R, et al. Comprehensive radionuclide esophagogastrointestinal transit study: methodology, reference values, and initial clinical experience. J Nucl Med. 2015;56:721-727.

19. Tougas G, Eaker E, Abell TL, et al. Assessment of gastric emptying using a low fat meal: establishment of international control values. Am J Gastroenterol. 2000;95:1456-1462.

20. Solnes LB, Sheikhbahaei S, Ziessman HA. Nuclear scintigraphy in practice: gastrointestinal motility. AJR. 2018;211:260-266.

21. Waller SL. Differential measurement of small and large bowel transit times in constipation and diarrhea. A new approach. Gut. 1975;16:372-378.

22. Caride VJ, Prokop EK, Troncale FJ, et al. Scintigraphic determination of small intestinal transit time: comparison with hydrogen breath technique. Gastroenterology. 1984;86:714-720.

23. Malagelada J-R, Robertson JS, Brown ML, et al. Intestinal transit of solid and liquid components of a meal in Health. Gastroenterology. 1984;87:1255-1263.
24. von der Ohe MR, Camilleri M. Measurement of small bowel and colonic transit: indications and methods. Mayo Clin Proc. 1992;67:1169-1179.

25. Camilleri M, Colemont LJ, Phillips SF, et al. Human gastric emptying and colonic filling of solids characterized by a new method. Am J Physiol. 1989;257:G284G290.

26. Smart RC, McLean RG, Gastron-Parry D, et al. Comparison of oral iodine-131 cellulose and Indium-111-DTPA as tracers for colonic transit scintigraphy: analysis by colon activity profiles. J Nucl Med. 1991;32:1668-1674.

27. Lundin E, Graf W, Garske U, et al. Segmental colonic transit studies: comparison of a radiological and a scintigraphic method. Colorectal Dis. 2007;9: 344-351.

28. Stivland T, Camilleri M, Vassallo M, et al. Scintigraphic measurement of region gut transit in idiopathic constipation. Gastroenterology. 1991;101:107115 .

29. Kuo B, Maneerattanaporn M, Lee AA, et al. Generalized transit delay on wireless motility capsule testing in patients with clinical suspicion of gastroparesis, small intestinal dysmotility or slow transit constipation. Dig Dis Sci. 2011;56: 2928-2938.

30. Camilleri M, Ford AC, Mawe GM, et al. Chronic constipation. Nat Rev Dis Primers. 2017;3:17095. 